\title{
Efeito da reutilização do implante de progesterona multidose na taxa de concepção de fêmeas Bos indicus paridas submetidas à inseminação artificial em tempo fixo
}

Camila Bizarro da Silva ${ }^{[a]}$, Camila Oliveira Rosa $a^{[a]}$, Maíra Moreira Santos ${ }^{[]^{\circ}}$, Paulo Roberto Pelaquim ${ }^{[b]}$, Felipe da Silva Pedroso ${ }^{[b]}$,

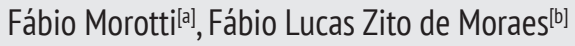

\footnotetext{
[a] Programa de Pós-graduação em Ciência Animal, Universidade Estadual de Londrina (UEL), Londrina, PR, Brasil

[b] Universidade Norte do Paraná (UNOPAR), Londrina, PR, Brasil
}

*Autor correspondente

e-mail: maira_moreira04@yahoo.com.br

\section{Resumo}

0 rebanho bovino brasileiro, constituído por cerca de 215 milhões de cabeças, é o segundo maior do mundo, representando $22,5 \%$ do rebanho mundial. 0 emprego de biotécnicas reprodutivas, tal como a inseminação artificial em tempo fixo (IATF), potencializa a eficiência reprodutiva e a produtividade, devido ao melhoramento genético do rebanho e a otimização das práticas de manejo. A fim de avaliar a influência do número de utilização do dispositivo de progesterona (P4) na taxa de concepção, o presente estudo analisou os dados de concepção de 1.791 fêmeas zebuínas paridas, submetidas à IATF empregandose dispositivo de diferentes usos. Os animais foram criados sob manejo extensivo Urochloabrizantha, sal mineral ad libitum e escore de condição corporal variando de 2,5 a 4,5 (escala de 1 a 5). Após a avaliação do trato reprodutivo, as vacas foram submetidas a um protocolo de IATF em um dia aleatório do ciclo estral (D0). Neste dia, cada vaca recebeu benzoato de estradiol (Sincrodiol ${ }^{\circledR} 2 \mathrm{mg}$, IM) e o dispositivo intravaginal de (P4) (Sincrogest ${ }^{\circledR} 1 \mathrm{~g}$ ) conforme seu uso: novo $(\mathrm{n}=711)$, de $2^{\circ}$ uso $(\mathrm{n}=627)$ e de $3^{\circ}$ uso $(n=453)$. A remoção do dispositivo e a administração de cipionato de estradiol (Sincro $\mathrm{CP}^{\circledR} 1 \mathrm{mg}$, IM), cloprostenol sódico (Sincrocio ${ }^{\circledR} 500 \mu \mathrm{g}$, IM) e gonadotrofina coriônica equina (SincroeCG ${ }^{\circledR} 300$ UI, IM) ocorreu noD8. No D10 (48h após a remoção), as vacas foram submetidas à inseminação artificial com sêmen convencional criopreservado. 0 diagnóstico de gestação foi realizado por ultrassonografia 30 dias após a IATF. A taxa de concepção foi analisada pelo teste de Qui-quadrado, adotando um nível de significância de 5\%. A taxa de concepção foi semelhante ( $\mathrm{P}=0,7419)$ entre os grupos de dispositivos novos $(47,1 \% ; 335 / 711)$, de $2^{\circ}$ uso $(47,5 \% ; 298 / 627)$ e de 3 o uso $(45,3 \% ; 205 / 453)$. A hipótese de que a taxa de concepção seria distinta de acordo com o número de uso do dispositivo Sincrogest ${ }^{\circledR}$ não se confirmou. A reutilização de dispositivos intravaginais de P4 em programas de IATF apresenta resultados variados conforme a categoria de fêmea 
utilizada, sendo que vaca parida representa a categoria de maior desafio. Outros estudos demonstram que os dispositivos contendo $1 \mathrm{~g}$ de $\mathrm{P} 4$ podem ser utilizados até duas vezes em protocolos de IATF de vacas de corte, sem comprometimento da eficácia. 0 presente estudo demonstrou que o dispositivo Sincrogest ${ }^{\circledR}$ pode ser utilizado até três vezes no protocolo de IATF de vacas zebuínas paridas, com resultados satisfatórios. Conclui-se que a taxa de concepção de vacas Bosindicusparidas submetidas à IATF não sofre influência do uso do dispositivo intravaginal de P4. 